\title{
The association of Streptococcus bovis/gallolyticus with colorectal tumors: The nature and the underlying mechanisms of its etiological role
}

\author{
Ahmed S Abdulamir*, Rand R Hafidh, Fatimah Abu Bakar
}

\begin{abstract}
Streptococcus bovis (S. bovis) bacteria are associated with colorectal cancer and adenoma. S. bovis is currently named S. gallolyticus. 25 to $80 \%$ of patients with S. bovis/gallolyticus bacteremia have concomitant colorectal tumors. Colonic neoplasia may arise years after the presentation of bacteremia or infectious endocarditis of $S$. bovis/gallolyticus. The presence of S. bovis/gallolyticus bacteremia and/or endocarditis is also related to the presence of villous or tubular-villous adenomas in the large intestine. In addition, serological relationship of S. gallolyticus with colorectal tumors and direct colonization of S. gallolyticus in tissues of colorectal tumors were found. However, this association is still under controversy and has long been underestimated. Moreover, the etiological versus non-etiological nature of this associationis not settled yet. Therefore, by covering the most of up to date studies, this review attempts to clarify the nature and the core of S. bovis/gallolyicus association with colorectal tumors and analyze the possible underlying mechanisms.
\end{abstract}

\section{Introduction \& statement of the problem}

One of the bacterial agents that has been found to be regularly associated with colorectal cancer is Streptococcus bovis (S. bovis). S. bovis has been shown to have important impact on health since 25 to $80 \%$ of patients with $S$. bovis bacteremia have colorectal tumors and the incidence of association of colonic neoplasia with $S$. bovis endocarditis has been shown to be 18 to $62 \%$ [1-7]. It was shown that $94 \%$ of $S$. bovis bacteremia associated with colorectal cancer was in fact $S$. bovis biotype I while only $18 \%$ was associated with biotype II [8]. Later, a new species resembling $S$. bovis was detected which was named S. gallolyticus [9]. Interestingly, $S$. bovis biotype I and II/2 isolates were then found to be S. gallolyticus [10]. Accordingly, S. bovis biotype I was renamed as $S$. gallolyticus subspecies gallolyticus and biotype II/2 was renamed as S. gallolyticus subspecies pasterianus and S. gallolyticus subspecies macedonicus [11] (Table 1). S. gallolyticus subspecies gallolyticus bacteria, more than other related taxa, have been found to be constantly associated with underlying colorectal

\footnotetext{
* Correspondence: ahmsah73@yahoo.com
Institute of Bioscience, University Putra Malaysia, 43400 Serdang, Selangor,

* Correspondence: ahmsah73@yahoo.com
Institute of Bioscience, University Putra Malaysia, 43400 Serdang, Selangor, Malaysia
}

(ㄷ) 2011 Abdulamir et al; licensee BioMed Central Ltd. This is an Open Access article distributed under the terms of the Creative Commons Attribution License (http://creativecommons.org/licenses/by/2.0), which permits unrestricted use, distribution, and reproduction in any medium, provided the original work is properly cited.

\section{Bacterial pathogens and cancer}

Traditionally, bacterial infections have not been considered a major cause of cancer. However, bacteria have been linked to cancer by two mechanisms: chronic inflammation and production of carcinogenic metabolites [12]. It was stated that bacteria in general are thought to contribute to carcinogenesis by the formation

Unfortunately, the nature of the association between $S$. underestimated. It has been controversial whether the carditis with colorectal tumors is merely a consequence of the gastrointestinal lesion or it could be of etiological nature. Furthermore, there is a growing need to highlight the possible mechanisms that $S$. bovis/gallolyticus might play in triggering or promoting colorectal cancer, if any. Moreover, the relationship of this bacterium with oncogenic factors, cell growth factors, and pro-inflamnature and the underlying mechanisms of the association of S. bovis/gallolyticus with colorectal cancer. 


\begin{tabular}{|c|c|c|}
\hline $\begin{array}{l}\text { Old } \\
\text { nomenclature }\end{array}$ & $\begin{array}{l}\text { Later } \\
\text { nomenclature }\end{array}$ & Recent nomenclature \\
\hline $\begin{array}{l}\text { S. bovis } \\
\text { biotype I }\end{array}$ & S. gallolyticus & S. gallolyticus subsp. gallolyticus \\
\hline \multirow{2}{*}{$\begin{array}{l}\text { S. bovis } \\
\text { biotype II/1 }\end{array}$} & S. infantarius & S. infantarius subsp. infantarius \\
\hline & $\begin{array}{l}\text { S. infantarius } \\
\text { subsp. Coli }\end{array}$ & S. lutetiensis \\
\hline $\begin{array}{l}\text { S. bovis } \\
\text { biotype } \| / 2\end{array}$ & $\begin{array}{l}\text { S. pasteurianus S. } \\
\text { macedonicus }\end{array}$ & $\begin{array}{l}\text { S. gallolyticus subsp. Pasteurianus } \\
\text { S. gallolyticus subsp. macedonicus }\end{array}$ \\
\hline
\end{tabular}

of potentially toxic by-products of carbohydrates or bile acid metabolism, as well as hydrolysis of other mutagenic precursors [12].

The association of Helicobacter pylori (H. pylori) with gastric cancer is the best studied relationship between a bacterial infection and cancer [13]. H. pylori has been recognized as a class I human gastric carcinogen by the International Agency for Research on Cancer [14]. The mechanisms by which bacteria contribute to cancer formation are complex and involve the interplay among chronic inflammation, direct microbial effects on host cell physiology, and changes in tissue stem cell homeostasis [15]. In fact, researchers in the field recently started to be sure that some chronic bacterial infections are associated with tumors formation; so, it might be possible to prevent or treat some forms of cancer if the infectious source was addressed [16].

A marked resurgence of interest in the gastrointestinal commensal flora and local host-microbe interactions was observed since it was recognized that intestinal bacteria could be implicated in the pathogenesis of several inflammatory diseases like Crohn's disease or ulcerative colitis [17]. Both diseases are commonly suspected to result from altered host responses to intestinal bacterial flora [18], and are associated with cancer risk [17,19-21]. Accordingly, World Health Organization considered bacteria as possible causative agents for cancer development.

\section{Colorectal cancer and infection}

The incidence of colorectal cancer varies widely among countries. In the developed world, colorectal cancer represents a major public health problem. In the UK and the USA, colorectal cancer is the second most common cancer after breast cancer for women, and prostate or lung cancer for men [22-25].

The involvement of intestinal microflora in the pathogenesis of colon cancer has been hypothesized. Many cancers arise from sites of infection, chronic irritation, and inflammation [26]. The strongest association of chronic inflammation with malignant diseases is found in inflammatory bowel diseases of colon [27] with a lifetime incidence of $10 \%$ [28,29].

The gut is colonized by many species of bacteria, and it is nearly impossible to narrow carcinogenesis to one organism, but it is possible that a specific bacterium may cause a favorable microclimate for mutagens to inflict their damage [12]. Some studies provided evidence that some colorectal cancers might be caused by infectious agents. One group of researchers found that bacterial methyltransferases induce mutations in tumor suppressor genes [30]. Another group found that some microflora might serve as promoters while others might serve as anti-promoters of colorectal carcinogenesis [31]. A third group concentrated their studies on colicins, which were found to exert antitumor effects [32,33].

Later studies showed that cytokine-based sequel of long-standing bacterial inflammation might be the main mechanism of transformational changes in normal colorectal mucosa. In $H$. pylori infections, the gastric levels of cytokines were found to correlate strongly with inflammation and the degree of gastritis [21,34]. It was also reported that colonic cells exposed in vitro to Clostridium difficile toxin A showed induced cytokines production [35,36]. Alike, S. bovis/gallolyticus bacteria, especially their cell wall antigens, were found to increase remarkably the production of inflammatory cytokines in the colonic mucosa of rats, suggesting direct interaction between $S$. bovis and colonic mucosal cells which is thought to lead to the development of colorectal cancer [37-40]. Hence, collectively, the bacterial etiology/predisposition of colorectal cancer has become evidently prevailing in the field of research which necessates intensive evaluation of the current trend of research done in this field.

\section{The association of S. bovis/gallolyticus bacteremia/ endocarditis with colorectal cancer}

S. bovis was traditionally considered as a lower grade pathogen frequently involved in bacteremia and endocarditis. Although McCoy and Mason [41] suggested a relationship between colonic carcinoma and the presence of infectious endocarditis in 1951, it was only in 1974 that the association of S. bovis and colorectal neoplasia was recognized [42]. Nevertheless, the extent, nature, and basis of this association are still not completely understood. A recent study [43] sequenced the 2,350 Kb genome of $S$. gallolyticus and analyzed 2,239 encoded proteins; they found that this bacterium synthesizes many proteins and polysaccharides for the assembly of capsular sheath, collagen-binding proteins, and three types of pili that all render this bacterium highly efficient in causing bacteremia, endocarditis, and colorectal cancer. 
The association of S. bovis/gallolyticus bacteremia/ endocarditis with colorectal cancer was assessed by numerous studies. It was found that 25 to $80 \%$ of patients with $S$. bovis/gallolyticus bacteremia and 18 to $62 \%$ of patients with $S$. bovis/gallolyticus endocarditis have underlying colorectal tumors $[1-7,44,45]$. The high rate of this association indicates serious clinical impact given that S. bovis/gallolyticus accounts for $14 \%$ of the cases of infectious endocarditis, and $13 \%$ of all cases of infectious endocarditis are caused by bacteria of gastrointestinal origin [46]. A study conducted for 18 years in Spain showed increased incidence of infective endocarditis cases casued by $S$. bovis/gallolyticus indicating that S. bovis/gallolyticus bacteremia/endocarditis is an emergent disease [45]. Thorough studies on S. bovis showed that the association between $S$. bovis bacteraemia and carcinoma of the colon and infective endocarditis is biotype-specific. It was shown that there is $94 \%$ association between $S$. bovis biotype I bacteraemia and infective endocarditis and $71 \%$ association between S. bovis biotype I bacteraemia and colonic carcinoma while it is only $18 \%$ association between $S$. bovis biotype II bacteraemia and infective endocarditis and 17\% association between $S$. bovis biotype II bacteraemia and colonic carcinoma [8]. Following the description of S. gallolyticus, Devriese team used whole-cell protein analysis showing that the bacterial isolates studied by his team, which were derived from patients with endocarditis and identified by conventional techniques as $S$. bovis, were in fact S. gallolyticus. Therefore, they suggested that S. gallolyticus is more likely to be involved in human infections than S. bovis [10].

The wide range of the association rates between $S$. bovis/gallolyticus and colorectal cancer might be attributed to different geographical and ethnic groups studied so far [47]. In a study conducted in Hong Kong, S. bovis biotype II/2 (S. gallolyticus subspecies pasterianus), rather than biotype I (S. gallolyticus subspecies gallolyticus), was found to be dominantly associated with colorectal tumors [48] while, in Europe and the USA, $S$. gallolyticus subspecies gallolyticus is dominantly associated with colorectal tumors [10,47].

Beside the characteristic adhesive traits of $S$. bovis/gallolyticus to the intestinal cells, it is also known that, in contrast to most $\alpha$-haemolytic streptococci, S. bovis/gallolyticus is able to grow in bile [49] Therefore, unlike other bacteria, S. bovis/gallolyticus can bypass efficiently the hepatic reticulo-endothelial system and access systemic circulation easily which might explain the route responsible for the association between $S$. bovis/gallolyticus colonic lesions and S. bovis/gallolyticus bacteremia [50]. In this regard, an association was found between $S$. bovis/gallolyticus bacteraemia/endocarditis and liver disease [50]. The prevalence of chronic liver disease in patients with S. bovis/gallolyticus endocarditis was significantly higher than in patients with endocarditis caused by another aetiology (60\% vs $15.3 \%$ ) [51]. The rate of simultaneous occurrence of liver disease and colon cancer in patients with $S$. bovis/gallolyticus endocarditis/bacteraemia was found to be $27 \%$ [4]. Therefore, it was inferred that the association of S. bovis/gallolyticus bacteraemia/endocarditis with colorectal neoplasia indicates special pathogenic traits of this bacteria rendering it capable of entering blood circulation selectively through hepatic portal route. Accordingly, it was recommended that the liver as well as the bowel should be fully investigated in patients with $S$. bovis/gallolyticus endocarditis/bacteraemia [4,50-52]. Nevertheless, this does not exclude the possibility that other intestinal bacteria might be associated with colon cancer; a rare report stated that cases of Klepsiella pneumoniae liver abscess were found to be associated with colon cancer $[53,54]$.

\section{The extra colonic affection of S. bovis/gallolyticus bacteria}

Beside infective endocarditis, case reports suggested the possibility of infections by S. bovis/gallolyticus in various sites outside colorectum such as osteomyelitis, discitis [55] and neck abscess [56] which could be linked to colonic malignancy or malignancies in other locations. Although many studies suggested that infective endocarditis is the commonest manifestation of S. bovis/ gallolyticus infection in western countries [5-7,50], cholecystitis, cholangitis, and biliary tract diseases were reported to be commonest manifestations in other geographical areas, such as Hong Kong [48].

In addition, it was found that $S$. bovis/gallolyticus bacteremia is associated with malignancy irrespective of site; $29 \%$ of patients with positive S. bovis/gallolyticus bacteremia harbored tumor lesions in the colon, duodenum, gallbladder, pancreas, ovary, uterus, lung, or hematopoietic system [57]. Moreover, other studies observed the occurrence of $S$. bovis/gallolyticus bacteremia in patients with pancreatic cancer [58,59], squamous cell carcinoma of the mouth $[59,60]$, endometrial cancer [61], melanoma metastatic to the gastrointestinal tract [62], lymphosarcoma [63], Kaposi sarcoma [64], esophageal carcinoma [65], gastric carcinoma [66], gastric lymphoma [67] and pancreatic carcinoma [68].

\section{The association of S. bovis/gallolyticus with colorectal adenoma}

High incidence of colorectal cancer in individuals with polyps was observed. Most cases of invasive colorectal adenocarcinomas were found to arise from pre-existing adenomatous polyps [69]. About 90\% of preinvasive neoplastic lesions of the colorectum are polyps or polyp 
precursors, namely aberrant crypt foci [70]. Neoplastic polyps are often referred to more specifically as adenomas or adenomatous polyps [71]. Adenomatous polyps are considered as good and few surrogate end point markers for colorectal cancer [70,72].

It would be of interest to scrutinize any relationship between S. bovis/gallolyticus and colonic polyps taking into account the type of polyp and its malignant potential [11,47]. The relationship between S. bovis/gallolyticus infection and the progressive development of malignant disease in preneoplastic adenomatous polyps was supported by recent reports [39,73,74]. Interestingly, S. bovis/gallolyticus was found to be mildly associated with some benign lesions (diverticulosis, inflammatory bowel disease, cecal volvulus, perirectal abscess hemorrhoids, and benign polyps), while it was strongly associated with most malignant diseases (cancer and neoplastic polyps) of the colon $[2,39,67,70,75,76]$. It was also revealed that $S$. bovis/gallolyticus in patients with bacteremia and/or endocarditis is selectively related to the presence of the most aggressive type of polyps in the large intestine, villous or tubulovillous adenomas, $[76,77]$ In addition, Hoen team performed a case-control study on subjects underwent colonoscopy comparing between patients with $S$. bovis/gallolyticus endocarditis and sex- and age- matched unaffected patients. This study showed that colonic adenomatous polyps in the patients' group were twice as many cases as controls (15 of 32 vs 15 of 64), while lesions of colorectal cancer were present approximately 3 times as often as controls (3 of 32 vs 2 of 64) [78]. On the other hand, another study [79] found that the association between S. bovis/ gallolyticus and adenoma is more evident than colorectal cancer; they reported that $36 \%$ of positive blood cultures of S. bovis/gallolyticus were found in proliferative lesions, $15 \%$ of cancers and $21 \%$ of adenomas. A recent study done by our team supported this concept [39] showing that the level of S. bovis/gallolyticus IgG antibodies in adenoma patients was higher than in colorectal cancer patients or control subjects. However, Burns et al. [75] did not get the same findings; they found that the incidence of S. bovis/gallolyticus carriage in all colons with polyps was intermediary between normal colons and colons with carcinoma; however, the difference did not achieve statistical significance.

Since there is evidence that colon cancer progresses from normal tissue to adenoma and then to carcinoma through an accumulation of genetic alterations [80], the remarkable association between S. bovis/gallolyticus and adenomatous polyps seems to be of importance. Although ulceration of neoplastic lesions might form a pathway for S. bovis/gallolyticus to enter the bloodstream [7], the association of S. bovis/gallolyticus bacteremia with non-ulcerated colonic polyps indicates an etiological/promoter role of S. bovis/gallolyticus in polyps progression $[81,82]$. Therefore, the possibility of S. bovis/gallolyticus to act as a promoter for the preneoplastic lesions worths consideration. Ellmerich et al. [37] supported this hypothesis. They treated normal rats with $S$. bovis wall extracted antigens; rats did not develop hyperplastic colonic crypts; however, $50 \%$ of rats, that already received a chemocarcinogen, developed neoplastic lesions upon receiving $S$. bovis wall extracted antigens. This indicated that $S$. bovis/gallolyticus might exert their carcinogenic activity in colonic mucosa when preneoplastic lesions are established. Therefore, the role of S. bovis/gallolyticus in the etiology and/or acceleration of the transformation of aberrant crypts to adenoma and to a cancer is being considered.

Accordingly, the knowledge of S. bovis/gallolyticus association with adenoma of colorectal mucosa has important clinical implications. If colorectal lesions could be discovered at an early stage, curative resection might become possible [83]. Thus, bacteremia due to $S$. bovis/gallolyticus should prompt rigorous investigation to exclude both endocarditis and tumors of the large bowel $[82,84]$. Therefore, it was concluded that the discovery of a premalignant proliferative lesion in patients with history of bacteremia/endocarditis justifies the exploration of the colon by barium enema and/or colonoscopy $[82,84]$.

\section{Etiological versus non-etiological role of S. bovis/ gallolyticus in the development of colorectal tumors}

The underlying mechanisms for the association of $S$. bovis/gallolyticus bacteremia/endocarditis with colorectal tumors have long been obscure. The possible reason behind that, maybe, S. bovis/gallolyticus is a member of intestinal flora in 2.5 to $15 \%$ of individuals; this usually leads scientists to counteract the malicious role of this bacteria $[44,75]$. Therefore, a big question is frequently asked whether S. bovis/gallolyticus plays an etiological role in the development of colorectal tumors or it is merely a marker of the disease.

There are many clues provide strong evidence for the etiological role of S. bovis/gallolyticus in colon cancer development. The striking association between bacteremia caused by $S$. bovis biotype I and both colonic neoplasia (71\%) and bacterial endocarditis (94\%), compared with bacteremias caused by the closely related organisms such as $S$. bovis variant and $S$. salivarius, suggests the possibility of specific bacterium-host cell interaction involving S. bovis biotype I organisms [85]. Later, S. gallolyticus subspecies gallolyticus, rather than other closely related taxa, was found to be actively colonizing colorectal tumors and primarily associated with colorectal cancer [40]. In addition, these bacteria showed special 
predilection to colonic lesions rather than other members of group D Streptococcus endocarditis. It was found that of 77 infections with group D Streptococcus endocarditis, colonic polyps and colonic carcinoma were significantly more frequent in the S. bovis/gallolyticus group, 67 and 18\%, than in the Enterococcus group, 21 and $2 \%$, respectively [3].

Furthermore, the appearance of new colonic lesions within 2 to 4 years after the incidence of S. bovis/gallolyticus bacteremia/endocarditis provides clearer evidence that $S$. bovis/gallolyticus is not merely a consequence of the tumor lesion [86]. For this reason, patients with infectious endocarditis and normal colonoscopy may be included in the group that presents risk for developing colonic cancer because of the late appearance of such lesions after the infectious episode of $S$. bovis/ gallolyticus.

In terms of pathogenesis, as S. bovis/gallolyticus is a transient normal flora in the gut, researchers have postulated that the increased load of S. bovis/gallolyticus in colon might be responsible for its association with colon cancer. Several studies showed increased stool carriage of $S$. bovis/gallolyticus in patients with inflammatory bowel diseases or malignant/premalignant lesions of the colon; around $56 \%$ of patients with S. bovis/gallolyticus bacteremia/endocarditis showed increased faecal carriage, when compared to normal subjects or patients with benign diseases of the colon, such as colonic diverticulosis, inflammatory bowel disease, cecal volvulus, perirectal abscess and hemorrhoids (10-23\%) [2,67,75].

Another clue supporting the etiological role of $S$. bovis/gallolyticus, patients diagnosed with colon cancer have only $3-6 \%$ chance to develop S. bovis/gallolyticus bacteremia/endocarditis [87]; this is far lower than the percentage of the detection of colorectal cancer in patients with S. bovis/gallolyticus bacteremia/endocarditis, $>70 \%$.

S. bovis/gallolyticus is shown to have indiscriminate pathogenic factors. It can uniquely colonize the thrombin of platelets and fibrin where colonies become developed with protection from new layers of platelets and fibrin that are formed by stimulation from thromboplastin; hence, S. bovis/gallolyticus can penetrate into the bloodstream through epithelial, oropharyngeal, dermal, respiratory, gastrointestinal, or urogenital lesions [88]. On the other hand, the ulceration of neoplastic lesions are found to be unable to form a consistent pathway for the gut microorganisms to enter the bloodstream [7]. The access of $S$. bovis/gallolyticus into blood circulation does not explain the cases of patients with infectious endocarditis and non-ulcerated colonic polyps [81].

Above all, S. bovis/gallolyticus bacteria were found to be actively engaged in triggering severe inflammatory reaction in colorectal mucosa, inducing inflammatory and angiogenic cytokines leading to the formation of free radicals that are implicated in the development or propagation of all types of human cancers [27,29,37,39,40,89].

Accordingly, too many clues were found supporting the etiological role of $S$. bovis/gallolyticus in the development of colorectal tumors; therefore, it is very difficult to assume a non-etiological role of these bacteria. Hence, a more detailed overview is needed to clarify the underlying mechanisms that could be pursued by $S$. bovis/gallolyticus for the etiology or propagation of colorectal tumors.

\section{The hypothesized mechanisms of the etiological association of S. bovis/gallolyticus with colorectal tumors}

The other big question in the current topic, what mechanisms S. bovis/gallolyticus undertakes to induce, promote, or/and progress the development of neoplastic lesions. The most possible mechanisms are as follows:

\section{Carcinogenesis via cytokine-dependent inflammation}

Chronic inflammation is associated with many malignant changes. Host genetic polymorphisms of the adaptive and innate immune response play an important role in bacteria-induced cancer formation [90-92]. Therefore, studying the immunological responses to chronic bacterial infections yields important clues on the carcinogenic mechanisms of bacterial persistent infections and clarifies the relationship between inflammation and cancer $[93,94]$. Clinical studies have shown that the use of nonsteroidal anti-inflammatory drugs is associated with reduced risk of gastrointestinal cancers [95]; hence, these studies provide evidence on the role of inflammation in the development of gastrointestinal cancers.

In vitro experiments showed that the binding of $S$. bovis wall extracted antigens to various cell lines, including human colonic cancer cells (Caco-2), stimulated the production of inflammatory cytokines by those cells $[38,96]$. In other studies, the production of inflammatory cytokines in response to $S$. bovis/gallolyticus, such as TNF- $\alpha$, IL-1 $\beta$, IL- 6 , and IL- 8 , is found to contribute to the normal defense mechanisms of the host $[89,97]$ leading to the formation of nitric oxide and free radicals such as superoxide, peroxynitrites, hydroxyl radicals, and alkylperoxy radicals $[96,98]$. Owing to their potent mutagenicity, all these molecular species can contribute to the neoplastic processes by modifying cellular DNA (Figure 1). On the other hand, the production of angiogenic factors in colonic mucosa, such as IL-8, which can be triggered by $S$. bovis/gallolyticus antigens, may also favor the progression of colon carcinogenesis $[39,40,89,99,100]$ (Figure 1). This resembles H. pylori infection for the development of chronic inflammation in the gastric mucosa [101]. Therefore, chronic infection 


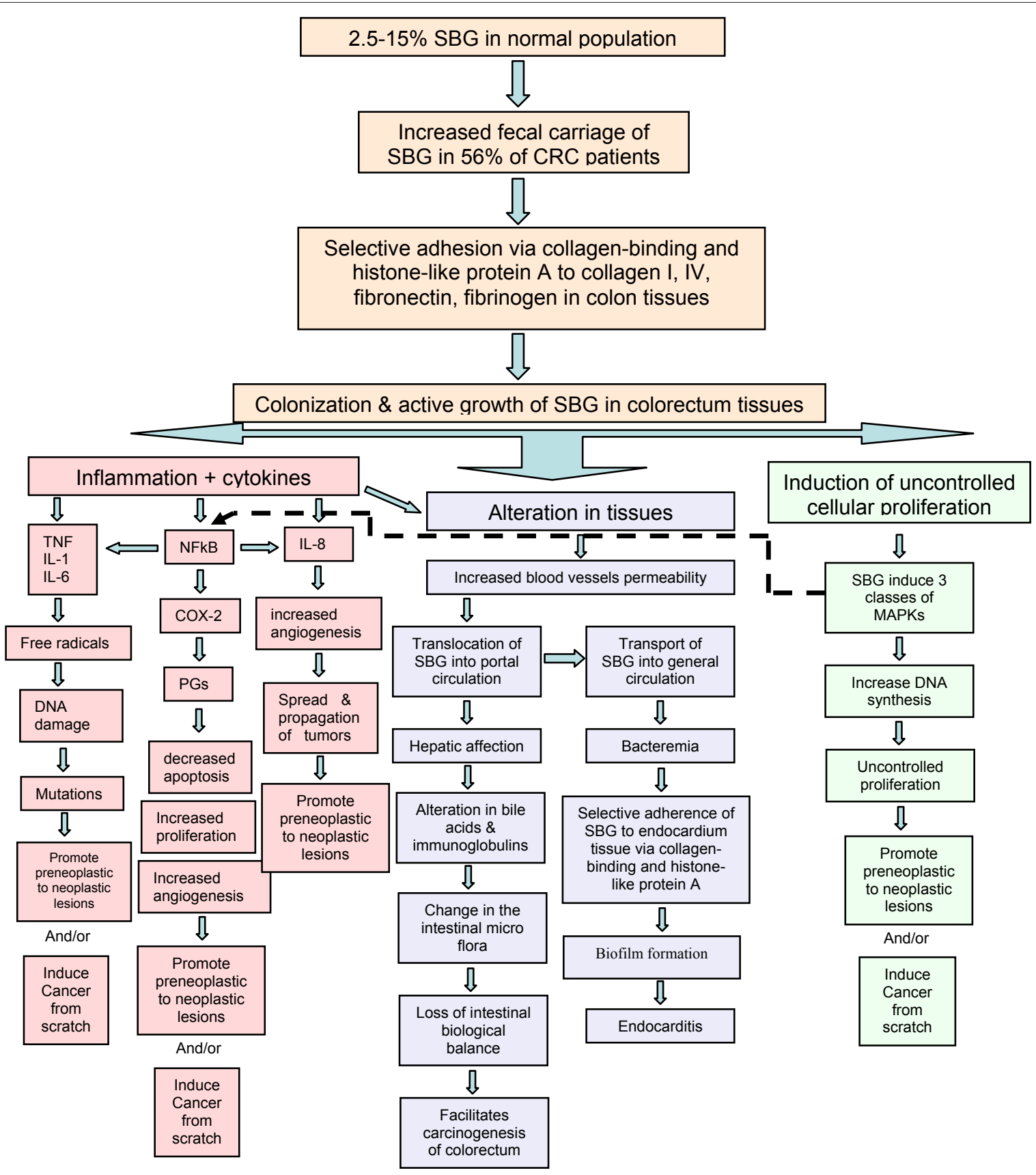

Figure 1 Illustration for the discovered and suggested mechanisms underlying the etiological association of S. bovis/gallolyticus (SBG) bacteria with promoting, propagating, or initiating colorectal tumors, bacteremia, and endocarditis.

and subsequent chronic inflammation seem responsible for the maintenance and development of pre-existing neoplastic lesions $[39,40,102]$.

Moreover, it was found that wall extracted antigens of $S$. bovis induced in vitro overexpression of cyclooxygenase-2 (COX-2) $[38,96]$. COX-2, via prostaglandins, promotes cellular proliferation and angiogenesis and inhibits apoptosis (Figure 1); thus it acts as a promoter in cancer pathway [103]. It is noteworthy to mention that non-steroidal anti-inflammatory drugs decrease the relative risk of gastrointestinal carcinomas through inhibiting the activity of COX-2 which is over-expressed in up to $85 \%$ of colorectal adenocarcinomas [104]. Alike, Haqqani et al., [105] revealed that the activation of leukocytes by $S$. bovis/gallolyticus releases various other inflammatory mediators (NO, free radicals, peroxynitriles, etc.) which could interfere directly or indirectly with the cell proliferation process. 
The recent studies conducted by our team revealed that $S$. gallolyticus is remarkably associated with colorectal cancer and adenoma when compared to the more dominant intestinal bacteria, $B$. fragilis. This provided evidence for a possible important role of S. gallolyticus in the carcinogenesis of colorectal cancer from premalignant polyps. In addition, we found that NF- $\kappa \mathrm{B}$ and IL-8 rather than other transformation factors, p21, p27 and p53 acted as highly important mediators for the $S$. gallolyticus- associated progression of colorectal adenoma to carcinoma [39]. And NF- $\kappa \mathrm{B}$ most probably exerts a promoting carcinogenic effect while IL-8 exerts an angiogenic/propagating effect on colorectal mucosal cells [39]. In addition, a more recent study done by our team showed a direct and active role of S. bovis/gallolyticus in colonizing colorectal cancer tissues leading to the development of colorectal cancer through inflammation-based sequel via, but not limited to, IL-1, COX-2, and IL-8 [40].

Another aspect of inflammatory cytokines, the local action of cytokines or of chemical mediators is able to promote vasodilatation and the enhancement of capillary permeability, which in turn was found to support the bacterial entry at tumor sites, and increase bacterial adherence to various cells $[38,89]$. It has been suggested that alteration in local conditions and disruption of capillary channels at the site of neoplasm allowed $S$. bovis/gallolyticus to proliferate and gain entry into blood stream [37,38,40,96]. Therefore, S. bovis/gallolyticus shows characteristic potential in inducing mucosal inflammation and changing the mucosal microclimate leading most probably to tumor development and increased permeability of blood vessels which facilitates this bacterium to enter blood circulation causing bacteremia and/or endocarditits.

\section{Characteristic adherence potential}

Members of the S. bovis/gallolyticus group are frequent colonizers of the intestinal tract as well as endocardial tissues. However, their ability to adhere to and colonize host tissues was largely unknown. Sillanpaa et al., [106] found recently that $S$. bovis/gallolyticus bacteria possess collagen-binding proteins and pili responsible for adhesion to colorectal mucosa as well as to endocardium (Figure 1). On the other hand, Boleij et al., [107] found a histone-like protein A on the cell wall of S. gallolyticus able to bind heparan sulfate proteoglycans at the colon tumor cell surface during the first stages of infection. This protein is believed to be largely responsible for the selective adhesive potential of S. bovis/gallolyticus. In addition, Vollmer et al. [108] found recently that the adherence of S. bovis/gallolyticus to the extracellular matrix proteins, collagen I, II and IV, revealed the highest values, followed by fibrinogen, tenascin and laminin.
Moreover, all tested strains showed the capability to adhere to polystyrole surfaces and form biofilms [108]. Another study which assessed 17 endocarditis-derived human isolates, identified 15 S. gallolyticus subspecies gallolyticus, one S. gallolyticus subspecies pasteurianus (biotype II/2) and one S. infantarius subspecies coli (biotype II/1) for their in vitro adherence to components of the extracellular matrix. They found that S. gallolyticus subspecies gallolyticus has very efficient adherence characteristics to the host extracellular matrix; this bacteria showed powerful adherence to collagen type I and type IV, fibrinogen, collagen type V, and fibronectin [109] (Figure 1). These adherence criteria make S. gallolyticus subspecies gallolyticus a successful colonizer in both intestinal and cardiac tissues. Therefore, it has been stated that the relationship between S. bovis/gallolyticus endocarditis and S. bovis/gallolyticus colonic tumors suggests the existence of certain adhesins on the cell wall of these bacteria allowing the colonization of both colonic and vascular tissues [106,107].

\section{Altering the profile of bacterial flora}

The members of gut microflora contribute to several intestinal functions, including the development of mucosal immune system, the absorption of complex macromolecules, the synthesis of amino acids and vitamins, and the protection against pathogenic microorganisms. In order to keep the mutual relationship between the microflora and the intestinal function, it is important that microflora is continuously kept under control to preserve gut homeostasis. When this is not achieved or perturbed, several immune disorders can arise, like allergies, inflammation, and cancer $[110,111]$. Increased incidence of hepatic dysfunction was reported among patients with infectious endocarditis caused by S. bovis/gallolyticus [77]. Both colonic pathology and liver dysfunction were determined in 92 patients with S. bovis endocarditis/bacteremia. Colonic pathology was identified in $51 \%$, and liver disease or dysfunction was documented in $56 \%$ of patients with $S$. bovis/gallolyticus endocarditis/bacteremia [4]. It was conceived that either the underlying colonic disease or the alterations in hepatic secretion of bile salts or immunoglobulins may promote the overgrowth of $S$. bovis and its translocation from the intestinal lumen into the portal venous system [4] (Figure 1).

Alike, it has been speculated that S. bovis/gallolyticus affects portal circulation through bacterial translocation, thereby determining hepatic alterations. Modifications in the hepatic secretion of bile salts and the production of immunoglobulins contribute towards increasing the participation of S. bovis/gallolyticus in abnormal changes in the bacterial flora of the colonic lumen which might then promote carcinogenesis of the intestinal mucosa $[7,84]$. 


\section{Promoter of early preneoplastic lesions}

A series of interesting experiments was conducted to investigate the role of S. bovis/gallolyticus in the initiation versus the propagation of colorectal cancer. Chemical carcinomas of colon were induced by giving adult rats intraperitonial injections of azoxymethane $(15 \mathrm{mg} /$ kg body weight) once per week for 2 weeks. Fifteen days (week 4) after the last injection of the carcinogen, the rats received, by gavage twice per week during 5 weeks, either S. bovis ( $10^{10}$ bacteria) or its wall-extracted antigens $(100 \mu \mathrm{g})$. One week after the last gavage (week 10), it was found that administration of either S. bovis or its antigens promoted the progression of preneoplastic lesions, but not normal tissue, into neoplastic lesions through the increased formation of hyperproliferative aberrant colonic crypts, which enhanced the expression of proliferation markers and increased the production of IL-8 in the colonic mucosa $[38,89]$ (Figure 1). Therefore, it was suggested that $S$. bovis/gallolyticus acts as a potential promoter of early preneoplastic lesions in the colon of rats, and their cell wall proteins are more potent inducers of neoplastic transformation than the intact bacteria. Moreover, the development of colonic adenomas was increased remarkably in $50 \%$ of the tested rats together with the proliferation markers, namely the polyamine content and the proliferating cell nuclear antigen PCNA $[37,38,96]$. This provided extra evidence that $S$. bovis/gallolyticus acts more likely as promoter/ propagator of colorectal carcinoma rather than just a consequence of the tumor lesion. However, these studies might suggest that bacteria are not sufficient to induce cancer by their own. Hence, tumor development might require independent mutations in the oncogenic signaling pathways together with chronic inflammatory conditions which are needed to promote, propagate, and spread tumor lesions [88].

\section{Induction of uncontrolled cellular proliferation}

In the presence of wall extracted proteins of $S$. bovis/ gallolyticus, Caco-2 cells exhibited enhanced phosphorylation of 3 classes of mitogen activated protein kinases (MAPKs) [38]. Several reports showed that MAPKs activation stimulates cells to undergo DNA synthesis and cellular uncontrolled proliferation [112-114] (Figure 1). Therefore S. bovis/gallolyticus proteins could promote cell proliferation by triggering MAPKs which might increase the incidence of cell transformation and the rate of genetic mutations. Furthermore, MAPKs, particularly p38 MAPK, can induce COX-2 which is an important factor in tumorogenesis $[29,115]$ up-regulating the expression of NFkB which is considered the central link between inflammation and carcinogenesis, namely, inflammation-induced tumor progression [92].

\section{Colonization of Streptococcus gallolyticus in colorectal mucosa}

The association of S. bovis/gallolyticus with colorectal cancer has usually been described through the incidence of S. bovis/gallolyticus bacteremia and/or endocarditis $[1-4,44]$. On the other hand, little bacteriological research has been done [116,117] on elucidating the colonization of S. bovis/gallolyticus in tumor lesions of colorectal cancer to confirm or refute, on solid bases, the direct link between colorectal cancer and S. bovis/ gallolyticus. Previous studies [116,117] did not find clear evidence for the colonization of S. bovis/gallolyticus in colorectal tumors. This might be attributed to the complete reliance on bacteriological methods rather than more sensitive molecular assays for the detection of $S$. bovis/gallolyticus nucleic acids.

A recent study done by our team assessed the colonization of S. bovis/gallolyticus in the colon [40]. In this study, S. bovis/gallolyticus-specific primers and probes were used in PCR and in situ hybridization (ISH) assays, respectively, along with bacteriological isolation of $S$. bovis/gallolyticus to detect/isolate S. bovis/gallolyticus DNA/cells from feces, tumor mucosal surfaces, and from inside tumor lesions. S. bovis/gallolyticus was remarkably isolated, via bacteriological assays, from tumor tissues of colorectal cancer patients with history of bacteremia, $20.5 \%$, and without history of bacteremia, $12.8 \%$, while only $2 \%$ of normal tissues of age- and sexmatched control subjects revealed colonization of $S$. bovis/gallolyticus. On the other hand, the positive detection of S. bovis/gallolyticus DNA, via PCR and ISH assays, in tumor tissues of colorectal cancer patients with history of bacteremia, 48.7 and $46.1 \%$, and without history of bacteremia, 32.7 and $28.8 \%$, was remarkably higher than in normal tissues of controls, $4 \%$, and $2 \%$, respectively. In addition, by using absolute quantitative PCR for S. bovis/gallolyticus DNA, the S. bovis/gallolyticus count, in terms of copy number $(\mathrm{CN})$, in tumor tissues of colorectal cancer patients with history of bacteremia, 2.96-4.72 $\log _{10} \mathrm{CN} / \mathrm{g}$, and without history of bacteremia, 2.16-2.92 $\log _{10} \mathrm{CN} / \mathrm{g}$, was higher than the near-zero colonization in normal tissues. Moreover, the level of S.bovis/gallolyticus colonization in colorectal cancer patients with history of bacteremia was found significantly higher than in colorectal cancer patients without history of bacteremia (Figure 1). This study provided several new clues. First, S. bovis/gallolyticus colonizes actively the lesion tissues of colorectal cancer patients rather than normal mucosal tissues. Second, the colonization of S. bovis/gallolyticus is mainly found inside tumor lesions rather than on mucosal surfaces. Third, the titer of the colonizing S. bovis/gallolyticus in colorectal cancer patients with history of bacteremia/ endocarditis is much higher than in patients without 
history of bacteremia/endocarditis; this explains why some colorectal cancer patients develop concomitant bacteremia/endocarditis while others do not. Actually, the newly found selective colonization of S. bovis/gallolyticus explains the conclusions of an earlier report [118] stating that colonic lesions provide a suitable microenvironment for S. bovis/gallolyticus colonization resulting in silent tumor-associated infections that only become apparent when cancer patients become immunocompromised, as in bacteraemia, or have coincidental cardiac valve lesions and develop endocarditis. An earlier study conducted by Swidsinski team [119] found similar results to our study [40] but on different bacteria. They quantified bacteria in colonic biopsy specimens of normal and cancer patients by polymerase chain reaction and found that the colonic mucosa of patients with colorectal carcinoma but not normal colonic mucosa was colonized by intracellular Escherichia coli.

\section{Early detection of colorectal cancer by detecting S. bovis/gallolyticus as one of the potential causative agents}

About $65 \%$ of population with age more than 60 years are at high risk for colorectal cancer which indicates the need for a proper screening test for the early detection of colorectal cancer [120]. For localized cancers, the five-year survival rate is approximately 90 percent for colon cancer and 80 percent for cancer of the rectum; this actually provides the suitable basis for improving patients' survival by applying reliable and early detection methods [30].

Very few studies were conducted to investigate the seroprevalence of $S$. bovis/gallolyticus among colorectal cancer patients. Seroprevalence of S. bovis/gallolyticus is considered as a candidate practical marker for the early prediction of an underlying bowel lesion at high risk population. It has been suggested that the presence of antibodies to S. bovis/gallolyticus antigens or the antigens themselves in the bloodstream may act as markers for the carcinogenesis in the colon $[84,87,116]$. In a study [121], it was stated that it might be possible to develop a test to screen patients for the presence of colonic cancer by measuring IgG antibody titer of $S$. bovis/gallolyticus. Moreover, the same report [121] revealed that there is a need for a good screening test for colonic cancer, particularly a test which could detect early lesions. The serology-based detection of colorectal cancer has advantages on other tests such as fecal occult blood which is neither sensitive nor specific or carcinoembryonic antigen which is regularly detectable in only advanced diseases [103].

Panwalker [122] revealed that the lack of any consistent difference in IgM antibody titer of $S$. bovis biotype I between colorectal cancer patients and control population suggests that the increased immune stimulation of colorectal cancer patients towards S. bovis occurs over a long period of time. Hence, since the association between slow evolving bacterial inflammation and colorectal cancer takes long time, it is prudent to seek specifically for IgG antibodies. Furthermore, IgG antibodies reflect an image of the past as well as the current presence of S. bovis/gallolyticus antigens in the circulation.

Some recent studies showed the possibility of constructing a serology test for the detection of colonic cancer based on the detection of antibody to S. bovis/gallolyticus or Enterococcus faecalis [39,123]. Therefore, a simple ELISA test with no more than $2 \mathrm{ml}$ of patient's blood might be a good candidate for screening high risk individuals for the presence of premalignant neoplastic polyps, adenomas, and cancers. However, some older studies of antibody response to $S$. bovis/gallolyticus and other streptococci have found that antibody is detectable in endocarditis but not in either clinically insignificant bacteremias [124], or colonic cancers [125] by using immunoblotting, immunoflourescence and other techniques.

In a recent study of our team [39], the level of IgG antibodies, measured via ELISA, against S. gallolyticus subspecies gallolyticus was found to be significantly higher in colorectal cancer patients than in control subjects. This is in full agreement with the study of Darjee and Gibb [121] who showed that patients with colonic cancer had higher median IgG antibody titers to S. bovis and E. faecalis preparations than did the control samples. Hence, the seroprevalence of IgG antibodies against S. gallolyticus subspecies gallolyticus showed the same behavior to that against $S$. bovis biotype I NCTC8133 [121].

A question might be asked, is it reliable to consider the seroprevalence of IgG antibodies against S. bovis/gallolyticus as an indicator for the detection of colorectal cancer given that S. bovis/gallolyticus is a member of intestinal microflora in 2.5 to $15 \%$ of normal individuals. In fact there are many factors support the concept of using the seroprevalence of $S$. bovis/gallolyticus as a detection tool. First, it was shown that the fecal carriage of $S$. bovis/gallolyticus increases in cases of colorectal cancer $[2,67,75]$. Second, S. bovis/gallolyticus has showed selective adhesion characteristics to the tumor tissue of colorectum [106,107]. Third, the alteration in local conditions and the disruption of capillary channels at the site of neoplasm allow S. bovis/gallolyticus to proliferate and gain entry into the blood stream, [38] which ultimately induces immune system to actively produce remarkable specific antibodies towards S. bovis/gallolyticus. Fourth, S. bovis/gallolyticus was shown to colonize tumor lesions selectively at high titers and this colonization is located deeply inside tumor tissues rather than superficially on mucosal surfaces; this feature increases 
the chances of triggering the systemic, along with mucosal, immune response leading to the development of anti- S. bovis/gallolyticus IgM and IgG antibodies [40]. Fifth, biochemical tests are not helpful diagnostic tools because of the wide variety of phenotypes seen in the $S$. bovis/gallolyticus complex; thus, instead, it is necessary to use serological or molecular methods [126].

\section{Conclusions}

It is concluded from the lump of research done in this field that S. bovis/gallolyticus association with colorectal tumors seems to be of etiological nature. And the proinflammatory potential of S. bovis/gallolyticus and their pro-carcinogenic properties including the leucocytic recruitment driven by $S$. bovis/gallolyticus, the tumor tissue- selective adhesion potential of $S$. bovis/gallolyticus, the selective colonization of $S$. bovis/gallolyticus in tumor cells, the suitable microenvironment of tumor tissues for the S. bovis/gallolyticus proliferation, the local disruption of tumor tissues and capillaries which allow the entry of S. bovis/gallolyticus into blood circulation, and the S. bovis/gallolyticus-induced cytokines and transcriptional factors, such as IL- 1 , IFN- $\gamma$, IL-8, and NFkB, all collectively provide evidence that $S$. bovis/gallolyticus is most probably responsible for a slow progressing carcinogenesis of colorectal mucosal tissues. Moreover, the S. bovis/gallolyticus- based carcinogenesis appears to occur through the transformation process from normal tissue to premalignant lesions, adenomas, to finally malignant cancerous tissues. And the proposed carcinogenic potential of $S$. bovis/gallolyticus is most likely a propagating factor for premalignant tissues. On the other hand, the early detection of colorectal adenomas or carcinomas via detection of S. bovis/gallolyticus DNA or their specific IgG antibodies might be of high value in screening high risk groups for colorectal cancer.

\section{Acknowledgements}

This review was done as a collaborative work of researchers who have long been involved in the field of colorectal cancer association with S. bovis/ gallolyticus. Therefore, sincere thanks for those who supported all prior pilot studies in this field.

\section{Authors' contributions}

AS and RR prepared the review data, collected the related references, analyzed the studied data and prior studies. AS, RR, and FAB drafted the review and prepared the review structure. all authors read and approved the final manuscript.

\section{Competing interests}

The authors declare that they have no competing interests.

Received: 29 September 2010 Accepted: 20 January 2011 Published: 20 January 2011

\section{References}

1. Wilson WR, Thompson RL, Wilkowske CJ, Washington JA, Giuliani ER, Geraci JE: Short-term therapy for streptococcal infective endocarditis.
Combined intramuscular administration of penicillin and streptomycin. JAMA , 2 1981, 245:360-363.

2. Reynolds JG, Silva E, McCormack WM: Association of Streptococcus bovis bacteremia with bowel disease. J Clin Microbiol 1983, 17:696-697.

3. Leport C, Bure A, Leport J, Vilde JL: Incidence of colonic lesions in Streptococcus bovis and enterococcal endocarditis. Lancet 1987, 1:748.

4. Zarkin BA, Lillemoe KD, Cameron JL, Effron PN, Magnuson TH, Pitt HA: The triad of Streptococcus bovis bacteremia, colonic pathology, and liver disease. Ann Surg 1990, 211:786-791, discussion 791-782.

5. Kok H, Jureen R, Soon CY, Tey BH: Colon cancer presenting as Streptococcus gallolyticus infective endocarditis. Singapore Med J 2007, 48:e43-45.

6. Malkin J, Kimmitt PT, Ou HY, Bhasker PS, Khare M, Deng Z, Stephenson I, Sosnowski AW, Perera N, Rajakumar K: Identification of Streptococcus gallolyticus subsp. macedonicus as the etiological agent in a case of culture-negative multivalve infective endocarditis by $16 \mathrm{~S}$ rDNA PCR analysis of resected valvular tissue. J Heart Valve Dis 2008, 17:589-592.

7. Gupta A, Madani R, Mukhtar H: Streptococcus bovis endocarditis; a silent sign for colonic tumour. Colorectal Dis 2010, 12(3):164-71.

8. Murray PR, Baron EJ: Manual of clinical microbiology. Washington, D.C.: ASM Press, 92007

9. Osawa R, Fujisawa T, LI S: Streptococcus gallolyticus sp. nov.: gallate degrading organisms formerly assigned to Streptococcus bovis. Syst Appl Microbiol 1995, 18:74-78.

10. Devriese LA, Vandamme P, Pot B, Vanrobaeys M, Kersters K, Haesebrouck F: Differentiation between Streptococcus gallolyticus strains of human clinical and veterinary origins and Streptococcus bovis strains from the intestinal tracts of ruminants. J Clin Microbiol 1998, 36:3520-3523.

11. Schlegel L, Grimont F, Ageron E, Grimont PA, Bouvet A: Reappraisal of the taxonomy of the Streptococcus bovis/Streptococcus equinus complex and related species: description of Streptococcus gallolyticus subsp. gallolyticus subsp. nov., S. gallolyticus subsp. macedonicus subsp. nov. and S. gallolyticus subsp. pasteurianus subsp. nov. Int I Syst Evol Microbiol 2003, 53:631-645.

12. Parsonnet J: Bacterial infection as a cause of cancer. Environ Health Perspect 1995, 103(Suppl 8):263-268.

13. Parsonnet J, Friedman GD, Vandersteen DP, Chang Y, Vogelman JH, Orentreich N, Sibley RK: Helicobacter pylori infection and the risk of gastric carcinoma. N Engl J Med 1991, 325:1127-1131.

14. WHO: monographs on the evaluation of carcinogenic risks to humans: schistosomes, liver flukes, and Helicobacter pylori. IARC 1994, 61:177-240.

15. Vogelmann R, Amieva MR: The role of bacterial pathogens in cancer. Curr Opin Microbiol 2007, 10:76-81.

16. Malfertheiner $P$, Sipponen $P$, Naumann M, Moayyedi $P$, Megraud F, Xiao SD, Sugano K, Nyren O: Helicobacter pylori eradication has the potential to prevent gastric cancer: a state-of-the-art critique. Am J Gastroenterol 2005, 100:2100-2115.

17. Teitelbaum JE, Triantafyllopoulou M: Inflammatory bowel disease and Streptococcus bovis. Dig Dis Sci 2006, 51:1439-1442.

18. Shanahan F: Probiotics in inflammatory bowel disease-therapeutic rationale and role. Adv Drug Deliv Rev 2004, 56:809-818.

19. Ekbom A, Helmick C, Zack M, Adami HO: Increased risk of large-bowel cancer in Crohn's disease with colonic involvement. Lancet 1990, 336:357-359.

20. Gilbert JM, Mann CV, Scholefield J, Domizio P: The aetiology and surgery of carcinoma of the anus, rectum and sigmoid colon in Crohn's disease. Negative correlation with human papillomavirus type 16 (HPV 16). Eur J Surg Oncol 1991, 17:507-513.

21. Chao C, Hellmich MR: Gastrin, inflammation, and carcinogenesis. Curr Opin Endocrinol Diabetes Obes 2010, 17:33-39.

22. Hewitson P, Glasziou P, Watson E, Towler B, Irwig L: Cochrane systematic review of colorectal cancer screening using the fecal occult blood test (hemoccult): an update. Am J Gastroenterol 2008, 103:1541-1549.

23. Greenlee RT, Hill-Harmon MB, Murray T, Thun M: Cancer statistics, 2001. CA Cancer J Clin 2001, 51:15-36.

24. Hawk ET, Limburg PJ, Viner JL: Epidemiology and prevention of colorectal cancer. Surg Clin North Am 2002, 82:905-941.

25. Parkin DM, Bray F, Ferlay J, Pisani P: Global cancer statistics, 2002. CA Cancer J Clin 2005, 55:74-108.

26. Miki C, Tanaka K, Toiyama Y, Inoue Y, Uchida K, Mohri Y, Kusunoki M: Comparison of the prognostic value of inflammation-based pathologic 
and biochemical criteria in patients undergoing potentially curative resection for colorectal cancer. Ann Surg 2010, 251:389-390, author reply 390-381.

27. Balkwill F, Mantovani A: Cancer and inflammation: implications for pharmacology and therapeutics. Clin Pharmacol Ther 2010, 87:401-406.

28. Choi PM, Zelig MP: Similarity of colorectal cancer in Crohn's disease and ulcerative colitis: implications for carcinogenesis and prevention. Gut 1994, 35:950-954.

29. Wang D, Dubois RN: The role of COX-2 in intestinal inflammation and colorectal cancer. Oncogene 2010, 29:781-788.

30. Mager DL: Bacteria and cancer: cause, coincidence or cure? A review. J Trans/ Med 2006, 4:14.

31. Killeen SD, Wang JH, Andrews EJ, Redmond HP: Bacterial endotoxin enhances colorectal cancer cell adhesion and invasion through TLR-4 and NF-kappaB-dependent activation of the urokinase plasminogen activator system. Br J Cancer 2009, 100:1589-1602.

32. Hal Nash R: Chronic Diseases With Possible Infectious Etiologies. 1999 [http://www.cdcgov/ncidod/EID/vol4no3/relman.htm].

33. Lancaster LE, Wintermeyer W, Rodnina MV: Colicins and their potential in cancer treatment. Blood Cells Mol Dis 2007, 38:15-18.

34. Taha AS, Kelly RW, Carr G, Stiemer B, Morton R, Park RH, Beattie AD: Altered urinary interleukin-8/creatinine ratio in peptic ulcer disease: pathological and diagnostic implications. Am J Gastroenterol 1996, 91:2528-2531.

35. Mahida YR, Makh S, Hyde S, Gray T, Borriello SP: Effect of Clostridium difficile toxin $A$ on human intestinal epithelial cells: induction of interleukin 8 production and apoptosis after cell detachment. Gut 1996, 38:337-347.

36. Castagnola E, Battaglia T, Bandettini R, Caviglia I, Baldelli I, Nantron M, Moroni C, Garaventa A: Clostridium difficile-associated disease in children with solid tumors. Support Care Cancer 2009, 17:321-324.

37. Ellmerich S, Scholler M, Duranton B, Gosse F, Galluser M, Klein JP, Raul F: Promotion of intestinal carcinogenesis by Streptococcus bovis. Carcinogenesis 2000, 21:753-756

38. Biarc J, Nguyen IS, Pini A, Gosse F, Richert S, Thierse D, Van Dorsselaer A, Leize-Wagner E, Raul F, Klein JP, et al: Carcinogenic properties of proteins with pro-inflammatory activity from Streptococcus infantarius (formerly S.bovis). Carcinogenesis 2004, 25:1477-1484.

39. Abdulamir AS, Hafidh RR, Mahdi LK, Al-jeboori T, Abubaker F: Investigation into the controversial association of Streptococcus gallolyticus with colorectal cancer and adenoma. BMC Cancer 2009, 9:403.

40. Abdulamir AS, Hafidh RR, Abu Bakar F: Molecular detection, quantification, and isolation of Streptococcus gallolyticus bacteria colonizing colorectal tumors: inflammation-driven potential of carcinogenesis via IL-1, COX-2, and IL-8. Mol Cancer 2010, 9:249.

41. McCoy W, Mason JM: Enterococcal endocarditis associated with carcinoma of the sigmoid; report of a case. J Med Assoc State Ala 1951, 21:162-166

42. Keusch GT: Opportunistic infections in colon carcinoma. Am J Clin Nutr 1974, 27:1481-1485.

43. Rusniok C, Couve E, Da Cunha V, El Gana R, Zidane N, Bouchier C, Poyart C, Leclercq R, Trieu-Cuot P, Glaser P: Genome sequence of Streptococcus gallolyticus: insights into its adaptation to the bovine rumen and its ability to cause endocarditis. J Bacteriol 2010, 192:2266-2276.

44. Murray HW, Roberts RB: Streptococcus bovis bacteremia and underlying gastrointestinal disease. Arch Intern Med 1978, 138:1097-1099.

45. Corredoira J, Alonso MP, Coira A, Casariego E, Arias C, Alonso D, Pita J, Rodriguez A, Lopez MJ, Varela J: Characteristics of Streptococcus bovis endocarditis and its differences with Streptococcus viridans endocarditis. Eur J Clin Microbiol Infect Dis 2008, 27:285-291.

46. Bisno A: Streptococcal infection. In Harrison's principles of internal medicine. 12 edition. Edited by: Harrison T, Stone R. New York: McGraw-Hill; 1991:563-569.

47. Boleij A, Schaeps RM, Tjalsma H: Association between Streptococcus bovis and colon cancer. J Clin Microbiol 2009, 47:516.

48. Lee RA, Woo PC, To AP, Lau SK, Wong SS, Yuen KY: Geographical difference of disease association in Streptococcus bovis bacteraemia. J Med Microbiol 2003, 52:903-908.

49. Luk WK, Liu CL, Yuen KY, Wong SS, Woo PC, Fan ST: Biliary tract infection due to bile-soluble bacteria: an intriguing paradox. Clin Infect Dis 1998, 26:1010-1012.
50. Vaska VL, Faoagali JL: Streptococcus bovis bacteraemia: identification within organism complex and association with endocarditis and colonic malignancy. Pathology 2009, 41:183-186.

51. Tripodi MF, Adinolfi LE, Ragone E, Durante Mangoni E, Fortunato $R$, larussi D, Ruggiero G, Utili R: Streptococcus bovis endocarditis and its association with chronic liver disease: an underestimated risk factor. Clin Infect Dis 2004, 38:1394-1400.

52. Osawa R, Sasaki E: Novel observations of genotypic and metabolic characteristics of three subspecies of Streptococcus gallolyticus. J Clin Microbiol 2004, 42:4912-4913.

53. Hsu WH, Yu FJ, Chuang CH, Chen CF, Lee CT, Lu CY: Occult colon cancer in a patient with diabetes and recurrent Klebsiella pneumoniae liver abscess. Kaohsiung J Med Sci 2009, 25:98-103.

54. Hiraoka A, Yamashita Y, Uesugi K, Koizumi Y, Yamamoto Y, Doi H, Hasebe A, Ichikawa S, Yano M, Miyamoto $Y$, et al: Three cases of liver abscesses complicated with colon cancer without liver metastasis: importance of screening for digestive disease. Intern Med 2007, 46:2013-2017.

55. Pedrajas Ortiz A, Macias Mir P, Ruiz Serrato A, Garcia Ordonez MA: [Aortic endocarditis and spondylodiscitis due to Streptococcus bovis in a patient in his eighties with colon cancer.]. Rev Esp Geriatr Gerontol 2010, 45(4):243-5.

56. Vince $K G$, Kantor SR, Descalzi J: Late infection of a total knee arthroplasty with Streptococcus bovis in association with carcinoma of the large intestine. J Arthroplasty 2003, 18:813-815.

57. Gold JS, Bayar S, Salem RR: Association of Streptococcus bovis bacteremia with colonic neoplasia and extracolonic malignancy. Arch Surg 2004, 139:760-765

58. Herrington CS, McGee JOD: Diagnostic molecular pathology: a practical approach. Oxford; New York: IRL Press at Oxford University Press; 1992.

59. Corredoira J, Alonso MP, Coira A, Varela J: Association between Streptococcus infantarius (formerly S. bovis II/1) bacteremia and noncolonic cancer. J Clin Microbiol 2008, 46:1570.

60. Gelfand MS, Alford RH: Streptococcus bovis endocarditis and squamouscell carcinoma of the mouth. N Engl J Med 1981, 305:284-285.

61. Anaf V, Noel JC, Thys JP, Simon P, Buxant F: A first case of Streptococcus bovis bacteremia and peritonitis from endometrial cancer origin. Acta Chir Belg 2001, 101:38-39.

62. Brooks R, Ravreby W, G K, Bottone E: More on Streptococcus bovis endocarditis and bowel carcinoma. N Engl J Med 1978, 298:572-573.

63. Levy B, von Reyn C, Arbeit R, Friedland J, Crumpacker C: More on Streptococcus bovis endocarditis and bowel carcinoma. N Engl J Med 1978, 298:572-573.

64. Glaser JB, Landesman SH: Streptococcus bovis bacteremia and acquired immunodeficiency syndrome. Ann Intern Med 1983, 99:878.

65. Pigrau C, Lorente A, Pahissa A, Martinez-Vazquez JM: Streptococcus bovis bacteremia and digestive system neoplasms. Scand J Infect Dis 1988, 20:459-460.

66. Kupferwasser I, Darius H, Muller AM, Mohr-Kahaly S, Westermeier T, Oelert H, Erbel R, Meyer J: Clinical and morphological characteristics in Streptococcus bovis endocarditis: a comparison with other causative microorganisms in 177 cases. Heart 1998, 80:276-280.

67. Klein RS, Catalano MT, Edberg SC, Casey Jl, Steigbigel NH: Streptococcus bovis septicemia and carcinoma of the colon. Ann Intern Med 1979, 91:560-562.

68. Gonzlez-Quintela A, Martinez-Rey C, Castroagudin JF, Rajo-Iglesias MC, Dominguez-Santalla MJ: Prevalence of liver disease in patients with Streptococcus bovis bacteraemia. J Infect 2001, 42:116-119.

69. CDC: Colorectal cancer: The importance of prevention and early detection. 2001 [http://www.cdcgov/cancer/colorct//colopdf/colaag01.pdf]

70. Nielsen SD, Christensen JJ, Laerkeborg A, Haunso S, Knudsen JD: [Molecular-biological methods of diagnosing colon-related Streptococcus bovis endocarditis]. Ugeskr Laeger 2007, 169:610-611.

71. Srivastava S, Verma M, Henson DE: Biomarkers for early detection of colon cancer. Clin Cancer Res 2001, 7:1118-1126.

72. Kelly C, Evans P, Bergmeier L, Lee SF, Progulske-Fox A, Harris AC, Aitken A, Bleiweis AS, Lehner T: Sequence analysis of the cloned streptococcal cell surface antigen I/II. FEBS Lett 1989, 258:127-132.

73. Kahveci A, Ari E, Arikan H, Koc M, Tuglular S, Ozener C: Streptococcus bovis bacteremia related to colon adenoma in a chronic hemodialysis patient. Hemodial Int 2010, 14:91-93. 
74. Murinello A, Mendonca P, Ho C, Traverse P, Peres H, RioTinto R, Morbey A, Campos C, Lazoro A, Milheiro A, et al: Streptococcus gallolyticus bacteremia assoaiced with colonic adenmatous polyps. GE-J-Port Gastrentrol 2006, 13:152-156.

75. Burns CA, McCaughey R, Lauter CB: The association of Streptococcus bovis fecal carriage and colon neoplasia: possible relationship with polyps and their premalignant potential. Am J Gastroenterol 1985, 80:42-46.

76. Smaali I, Bachraoui K, Joulek A, Selmi K, Boujnah MR: [Infectious endocarditis secondary to streptococcus bovis revealing adenomatous polyposis coli]. Tunis Med 2008, 86:723-724.

77. Fagundes J, Noujain H, Coy C, Ayrizono M, Góes J, Martinuzzo W: Associação entre endocardite bacteriana e neoplasias - relato de 4 casos. Rev Bras Coloproctol 2000, 20:95-99.

78. Hoen B, Briancon S, Delahaye F, Terhe V, Etienne J, Bigard MA, Canton P: Tumors of the colon increase the risk of developing Streptococcus bovis endocarditis: case-control study. Clin Infect Dis 1994, 19:361-362.

79. Devis A, Dony A, De Boelpaepe F, Verhulst C, Serste JP: [Streptococcus bovis septicemia and colonic cancer]. Acta Chir Belg 1989, 89:58-60.

80. Baron JA, Sandler RS: Nonsteroidal anti-inflammatory drugs and cancer prevention. Annu Rev Med 2000, 51:511-523.

81. Cutait R, Mansur A, Habr-Gama A: Endocardite por Streptococcus bovis e pólipos de cólon. Rev Bras Coloproctol 1988, 8:109-110.

82. Konda A, Duffy MC: Surveillance of patients at increased risk of colon cancer: inflammatory bowel disease and other conditions. Gastroenterol Clin North Am 2008, 37:191-213, viii.

83. Waisberg J, Matheus Cde O, Pimenta J: Infectious endocarditis from Streptococcus bovis associated with colonic carcinoma: case report and literature review. Arq Gastroenterol 2002, 39:177-180.

84. Beeching NJ, Christmas TI, Ellis-Pegler RB, Nicholson GI: Streptococcus bovis bacteraemia requires rigorous exclusion of colonic neoplasia and endocarditis. Q J Med 1985, 56:439-450.

85. Ruoff KL, Miller SI, Garner CV, Ferraro MJ, Calderwood SB: Bacteremia with Streptococcus bovis and Streptococcus salivarius: clinical correlates of more accurate identification of isolates. J Clin Microbiol 1989, 27:305-308.

86. Wentling GK, Metzger PP, Dozois EJ, Chua HK, Krishna M: Unusual bacterial infections and colorectal carcinoma-Streptococcus bovis and Clostridium septicum: report of three cases. Dis Colon Rectum 2006, 49:1223-1227.

87. zur Hausen $\mathrm{H}$ : Streptococcus bovis: causal or incidental involvement in cancer of the colon? Int J Cancer 2006, 119:xi-xii.

88. Balkwill F, Charles KA, Mantovani A: Smoldering and polarized inflammation in the initiation and promotion of malignant disease. Cancer Cell 2005, 7:211-217.

89. Ellmerich S, Djouder N, Scholler M, Klein JP: Production of cytokines by monocytes, epithelial and endothelial cells activated by Streptococcus bovis. Cytokine 2000, 12:26-31.

90. El-Omar EM: Role of host genes in sporadic gastric cancer. Best Pract Res Clin Gastroenterol 2006, 20:675-686.

91. Hou L, El-Omar EM, Chen J, Grillo P, Rabkin CS, Baccarelli A, Yeager M, Chanock SJ, Zatonski W, Sobin LH, et al: Polymorphisms in Th1-type cellmediated response genes and risk of gastric cancer. Carcinogenesis 2007, 28:118-123.

92. Karin M, Greten FR: NF-kappaB: linking inflammation and immunity to cancer development and progression. Nat Rev Immunol 2005, 5:749-759.

93. Ernst PB, Peura DA, Crowe SE: The translation of Helicobacter pylori basic research to patient care. Gastroenterology 2006, 130:188-206, quiz 212-183.

94. Monack DM, Mueller A, Falkow S: Persistent bacterial infections: the interface of the pathogen and the host immune system. Nat Rev Microbiol 2004, 2:747-765.

95. Dai $Y$, Wang WH: Non-steroidal anti-inflammatory drugs in prevention of gastric cancer. World J Gastroenterol 2006, 12:2884-2889.

96. Nguyen I, Biarc J, Pini A, Gosse F, Richert S, Thierse D, Van Dorsselaer A, Leize-Wagner E, Raul F, Klein J, et al: Streptococcus infantarius and colonic cancer: Identification and purification of cell wall proteins putatively involved in colorectal inflammation and carcinogenesis in rats. International Congress Series 2006, 257-261.

97. Travers P, Rosen FS: Immuno biology bookshelf the comprehensive resource on CD-ROM. [London; San Francisco] [New York]: Current Biology; Garland Pub, 2 1997, 1, CD-ROM.
98. Ohshima $\mathrm{H}$, Bartsch $\mathrm{H}$ : Chronic infections and inflammatory processes as cancer risk factors: possible role of nitric oxide in carcinogenesis. Mutat Res 1994, 305:253-264.

99. Norrby K: Interleukin-8 and de novo mammalian angiogenesis. Cell Prolif 1996, 29:315-323.

100. Eisma RJ, Spiro JD, Kreutzer DL: Role of angiogenic factors: coexpression of interleukin-8 and vascular endothelial growth factor in patients with head and neck squamous carcinoma. Laryngoscope 1999, 109:687-693.

101. Dixon MF, Genta RM, Yardley JH, Correa P: Classification and grading of gastritis. The updated Sydney System. International Workshop on the Histopathology of Gastritis, Houston 1994. Am J Surg Pathol 1996, 20:1161-1181.

102. Shacter E, Weitzman SA: Chronic inflammation and cancer. Oncology (Williston Park) 2002, 16:217-226, 229; discussion 230-212.

103. Tafte L, Ruoff K: Streptococcus bovis: Answers and Questions. Clin microbial newslett 2007, 29:49-55.

104. Kargman SL, O'Neill GP, Vickers PJ, Evans JF, Mancini JA, Jothy S: Expression of prostaglandin $\mathrm{G} / \mathrm{H}$ synthase-1 and -2 protein in human colon cancer. Cancer Res 1995, 55:2556-2559.

105. Haqqani AS, Sandhu JK, Birnboim HC: Expression of interleukin-8 promotes neutrophil infiltration and genetic instability in mutatect tumors. Neoplasia 2000, 2:561-568.

106. Sillanpaa J, Nallapareddy SR, Qin X, Singh KV, Muzny DM, Kovar CL, Nazareth LV, Gibbs RA, Ferraro MJ, Steckelberg JM, et al: A collagenbinding adhesin, Acb, and ten other putative MSCRAMM and pilus family proteins of Streptococcus gallolyticus subsp. gallolyticus (Streptococcus bovis Group, biotype I). J Bacteriol 2009, 191:6643-6653.

107. Boleij A, Schaeps RM, de Kleijn S, Hermans PW, Glaser P, Pancholi V, Swinkels DW, Tjalsma H: Surface-exposed histone-like protein a modulates adherence of Streptococcus gallolyticus to colon adenocarcinoma cells. Infect Immun 2009, 77:5519-5527.

108. Vollmer T, Hinse D, Kleesiek K, Dreier J: Interactions between endocarditisderived Streptococcus gallolyticus subsp. gallolyticus isolates and human endothelial cells. BMC Microbiol 2010, 10:78.

109. Sillanpaa J, Nallapareddy SR, Singh KV, Ferraro MJ, Murray BE: Adherence characteristics of endocarditis-derived Streptococcus gallolyticus ssp. gallolyticus (Streptococcus bovis biotype I) isolates to host extracellular matrix proteins. FEMS Microbiol Lett 2008, 289:104-109.

110. Rescigno M: The pathogenic role of intestinal flora in IBD and colon cancer. Curr Drug Targets 2008, 9:395-403.

111. Yang FJ, Jiao DA, Li SY: [Intestinal bacterial flora and cancer of the large bowel]. Zhonghua Liu Xing Bing Xue Za Zhi 1996, 17:52-53.

112. Ihler GM: Bartonella bacilliformis: dangerous pathogen slowly emerging from deep background. FEMS Microbiol Lett 1996, 144:1-11

113. Hirata Y, Maeda S, Mitsuno Y, Akanuma M, Yamaji Y, Ogura K, Yoshida H, Shiratori Y, Omata M: Helicobacter pylori activates the cyclin D1 gene through mitogen-activated protein kinase pathway in gastric cancer cells. Infect Immun 2001, 69:3965-3971.

114. Smith DG, Lawson GH: Lawsonia intracellularis: getting inside the pathogenesis of proliferative enteropathy. Vet Microbiol 2001, 82:331-345.

115. Lasa M, Abraham SM, Boucheron C, Saklatvala J, Clark AR: Dexamethasone causes sustained expression of mitogen-activated protein kinase (MAPK) phosphatase 1 and phosphatase-mediated inhibition of MAPK p38. Mol Cell Biol 2002, 22:7802-7811.

116. Potter MA, Cunliffe NA, Smith M, Miles RS, Flapan AD, Dunlop MG: A prospective controlled study of the association of Streptococcus bovis with colorectal carcinoma. J Clin Pathol 1998, 51:473-474.

117. Norfleet RG, Mitchell PD: Streptococcus bovis does not selectively colonize colorectal cancer and polyps. J Clin Gastroenterol 1993, 17:25-28.

118. Tjalsma H, Scholler-Guinard M, Lasonder E, Ruers TJ, Willems HL, Swinkels DW: Profiling the humoral immune response in colon cancer patients: diagnostic antigens from Streptococcus bovis. Int J Cancer 2006, 119:2127-2135

119. Swidsinski A, Khilkin M, Kerjaschki D, Schreiber S, Ortner M, Weber J, Lochs $\mathrm{H}$ : Association between intraepithelial Escherichia coli and colorectal cancer. Gastroenterology 1998, 115:281-286.

120. Rougier P, Mitry E: Epidemiology, treatment and chemoprevention in colorectal cancer. Ann Oncol 2003, 14(Suppl 2):ii3-5.

121. Darjee R, Gibb AP: Serological investigation into the association between Streptococcus bovis and colonic cancer. J Clin Pathol 1993, 46:1116-1119. 
122. Panwalker AP: Unusual infections associated with colorectal cancer. Rev Infect Dis 1988, 10:347-364.

123. Groves C: Case presentation. The Jhon Hokins Microbiology Newsletter 1997, 16:42-44.

124. Burnie JP, Holland M, Matthews RC, Lees W: Role of immunoblotting in the diagnosis of culture negative and enterococcal endocarditis. J Clin Pathol 1987, 40:1149-1158.

125. Kaplan MH, Chmel H, Stephens A, Hsieh HC, Tenenbaum MJ, Rothenberg IR, Joachim GR: Humoral reactions in human endocarditis due to Streptococcus bovis: evidence for a common $\mathrm{S}$ bovis antigen. $J$ Infect Dis 1983, 148:266-274

126. Herrera P, Kwon YM, Ricke SC: Ecology and pathogenicity of gastrointestinal Streptococcus bovis. Anaerobe 2009, 15:44-54.

127. Facklam R: What happened to the streptococci: overview of taxonomic and nomenclature changes. Clin Microbiol Rev 2002, 15:613-630.

doi:10.1186/1756-9966-30-11

Cite this article as: Abdulamir et al:: The association of Streptococcus bovis/gallolyticus with colorectal tumors: The nature and the underlying mechanisms of its etiological role. Journal of Experimental \& Clinical Cancer Research 2011 30:11.

\section{Submit your next manuscript to BioMed Central} and take full advantage of:

- Convenient online submission

- Thorough peer review

- No space constraints or color figure charges

- Immediate publication on acceptance

- Inclusion in PubMed, CAS, Scopus and Google Scholar

- Research which is freely available for redistribution

Submit your manuscript at www.biomedcentral.com/submit 